\title{
Maritime Security Cooperation: From Mistrust to Trust in the Indian Ocean Region
}

\author{
Bhagya Senaratne
}

\begin{abstract}
Home to one fifth of the world's waterbody, the Indian Ocean is abundant with a variety of mineral and biological resources. As the ocean space housing one of the world's busiest shipping routes, it is crucial that its natural resources and its environment are safeguarded. In ancient times, this ocean space has been an area of great cooperation, however, in present times the Indian Ocean has been largely confounded by distrust. The problem under study in this research was: even though the Indian Ocean Region is an extremely important and highly utilised ocean space that a vast majority of the world relies on, there is inadequate cooperation between the littoral states as well as the extra-regional states in ensuring the waterbody is safe. As such, the objectives of this research were to analyse why there is inadequate cooperation within the Indian Ocean Region; and to analyse how the Indian Ocean littoral countries and its users can cooperate with one another in ensuring maritime security cooperation. Primary sources for the qualitative research included policy documents and correspondence whilst secondary data included newspaper articles, reputed journals and websites. The data gathered from these sources were coded to derive the analysis in this research. As present challenges are diverse and dynamic, countries are singularly unable to ensure ocean spaces are safe unless they have shared intelligence and information from a variety of stakeholders. The paper argues that Maritime Domain Awareness enables intelligence sharing, as well as in exchanging capabilities and resources. In conclusion, there are many avenues for maritime security cooperation in the Indian Ocean such as by sharing capabilities, resources and skills. It can also cooperate to eliminate non-traditional security threats, which affects both the littoral states as well as the users of the Indian Ocean.
\end{abstract}

Keywords: Indian Ocean, Maritime Domain Awareness, Maritime Security Cooperation, Non-Traditional Security Threats

Bhagya Senaratne is a Senior faculty member at Department of Strategic Studies, General Sir John Kotelawala Defence University, Sri Lanka. She can be reached at senaratne.bhagya@gmail.com 


\section{Introduction}

As the third largest ocean in the world, the Indian Ocean Region (IOR) has a considerable area to be monitored and protected. Its dimensions and resources make it all the more important to be safeguarded. The Indian Ocean region has two types of users, i.e. the countries that are its littoral states, and those external; that use the Indian Ocean for purposes of transportation of goods, people and raw material. As the ocean space is vast and is used for purposes of transportation, it becomes important that this area is protected from being especially used for illegal activities. Illegal activities, which would ultimately cause problems to the security of the littoral states and the users of the Indian Ocean. In this context, this paper identifies Maritime Domain Awareness (MDA) as a possible solution to the problems experienced in the IOR and suggests measures both the littoral states as well as its external users together could take to safeguard the ocean along with its users.

Towards this end, this initial section is further sub-divided into two sections in order to provide definitions for the two main concepts - i.e. Maritime Domain Awareness and the Indian Oce an Region - that provides the foundation for the discussion in this paper.

\section{Maritime Domain Awareness}

The U.S. Department of Defense defines Maritime Domain Awareness as "the effective understanding of anything associated with the maritime domain that could impact the security, safety, economy, or environment of a nation" 1 . As such, MDA discusses about providing safety and security to a wide spectrum of issues such as the environment, economy and a country's traditional security to name a few. According to the National Concept of Operations for Maritime Domain Awareness, a maritime domain can be defined as areas related to or bordering a "sea, ocean, or other navigable waterway, including all maritime-related activities, infrastructure, people, cargo, and vessels and other

1 Marine Insight, A General Overview of Maritime Domain Awareness (MDA), July 21, 2016 https://www.marineinsight.com/maritime-law/a-general-overviewof-maritime-domain-awareness-mda/ 
conveyances". Therefore, it can be understood that awareness or monitoring of the maritime domain requires a lot of attention and resources, as it refers to and is relevant to any waterbody that can be navigated.

Further, MDA aims to "collect the maximum information and intelligence about any ship or vessel in the country's waters" in order to ensure the safety of its borders. Information such as this facilitates a country to prepare for security threats as well as implement pre-emptive measures. It further details MDA is about "deterring and preventing hostile or illegal acts within the maritime domain" 2 . It therefore intends to implement measures to safeguard its maritime boundaries by ensuring that there are less threats entering it. Whilst MDA is focused mainly on the USA and ensuring its safety, it can also be broadly used and exercised for the betterment of the world's oceanic regions as the concept discusses about collecting and sharing information and intelligence.

Maritime Domain Awareness entails "creating a collaborative information environment in which partners can monitor risks to their maritime interests while promoting the freedoms of navigation, civil liberties and maritime commerce" ${ }^{3}$. This showcase the potential and the ability for countries to collaborate and cooperate in sharing information on ocean spaces such as the Indian Ocean, which are available to them with other states. Sharing of vital information via initiatives such as MDA, would also improve the levels of trust between states.

2 National Concept of Operations for Maritime Domain Awareness, 2007, http://nmio.ise.gov/Portals/16/Docs/071213mdaconops.pdf?ver= $2015-12-04$ 123515-657

3 George Vance, and Paulo Vicente, “ Maritime Domain Awareness”, Proceedings of the Marine Safety \& Security Council, 63, no.3, (2006). 


\section{The Indian Ocean Region}

The Indian Ocean is the third largest ocean covering one-fifth of the planet's salt water-body. This ocean space is abundant with a variety of mineral and biological resources ${ }^{4}$. This space also comprises of 38 littoral states, 24 ocean territories and 17 landlocked countries covering the continents of Africa, Asia, Australia and Antarctica. The Pacific Ocean and the Atlantic Ocean connects with the Indian Ocean along with the Arabian Sea and the Red Sea, covering an area of 169,000 square miles $^{5}$. It is also plentiful with natural resources such as petroleum and natural gas reserves as well as many rich natural minerals, such as manganese nodules, ilmenite, tin etcetera and approximately five percent of the total Indian Ocean area consists of continental shelves. In addition to the above, this ocean space possesses a portion of the world's largest fishing grounds, providing approximately a quarter of the total world's fish catch.

Home to more than half of the world's known offshore oil reserves; the Indian Ocean is also an artery for the transportation of unfinished goods and cargoes, such as crude oil, iron, coal, rubber and tea. ${ }^{6}$ Nearly 50 percent of the world's container traffic passes through the Indian Ocean with a third of the world's trade being handled in its ports ${ }^{7}$. Furthermore, it is estimated that over 60,000 ships continue to sail from east to west and vice versa annually, carrying two thirds of oil and half of all container shipments. It is estimated that $70 \%$ of seaborne oil travels through

4 Indian Ocean, Encyclopedia Britannica, 2016, https://www.britannica.com/place/Indian-Ocean

5 Bhagya Senaratne,"The importance of public diplomacy in formulating a maritime policy for the Indian Ocean Region," Maritime Affairs: Journal of the National Maritime Foundation of India, (2016),10.1080/09733159.2016.1181393

6 Indian Ocean. 2016.

7 Dinusha Panditaratne, "The Role of Sri Lanka in South Asia and Beyond: Emerging New Contours," Research and Information System for Developing Countries. (January 19, 2018), https://www.lki.lk/wp-content/uploads/ 2018/02/LKI\%E2\%80\%99s-Dinusha-Panditaratne-on-the-Role-of-Sri-Lanka-inSouth-Asia-and-Beyond-at-RIS-in-India.pdf 
the Indian Ocean ${ }^{8}$. It must be noted that a majority of China's energy shipments are imported through the Indian Ocean region, which showcases that there is an inherent interest by China towards safeguarding these routes - the Sea Lanes of Communication (SLOCs) - as well as engaging with the region to ensure its imports are safe. India, as the resident power in the Indian Ocean also utilises this ocean space to transport approximately $60 \%$ of its exports and imports ${ }^{9}$. Therefore, as one of the world's busiest shipping routes, it is crucial that this ocean space, its natural resources and its environment at large are safeguarded for the future generations to come.

It must be noted that in ancient times, this ocean space has been an area of immense cooperation. Therefore, it is imperative that combined measures are taken to ensure that sustainable principles are practiced in order to make it a liveable environment for the future. For that reason, this paper illustrates the possibilities for cooperation in the Indian Ocean region among its littoral states as well as its users, such as extra regional powers.

\section{Research Problem}

Even though the Indian Ocean region is an extremely important and highly utilised ocean space that a vast majority of the world relies on, there is inadequate cooperation between the littoral states as well as its users, the extra-regional states. In this backdrop, cooperation via various mechanisms would enable Maritime Domain Awareness, a vital component in ensuring maritime security cooperation and in safeguarding the Indian Ocean for future generations.

As such this research paper endeavours to provide answers to three questions in unpacking the research problem stated above. The questions are: a) why is there inadequate cooperation within the Indian Ocean Region; b) how can the Indian Ocean littoral countries cooperate to ensure maritime security; c) how can users of the Indian Ocean cooperate via Maritime Domain Awareness in

8 Panditaratne, The Role of Sri Lanka in South Asia and Beyond.

9 "India" World Trade Organization, 2017, http://stat.wto.org/

CountryProfile/WSDBCountryPFView.aspx?Country=IN\&Language=F 
ensuring maritime security cooperation in the Indian Ocean. Answers to these questions are discussed in detail in a subseque nt section of this paper.

\section{Objectives and Research Methods}

The principal objective of this research was to analyse why there is inadequate cooperation within the Indian Ocean Region, thereby discussing how the Indian Ocean littoral countries can cooperate via Maritime Domain Awareness in ensuring their countries' physical borders and the environment of the Indian Ocean at large can be safe and secure. The secondary objective was to analyse how the Indian Ocean littoral countries and its users can cooperate with one another in ensuring maritime security cooperation, thereby identifying the role to be played by extraregional powers in ensuring the safety of this ocean space.

Accordingly, the study utilised a combination of primary and secondary sources of information. Primary sources such as conducting focus group discussions and interviews with naval personnel, accessing policy documents and correspondence were gathered to obtain qualitative data for the research study. The research also utilised secondary sources of data such as newspaper articles, reputed journal articles and websites. The data gathered from these sources were thematically coded to derive the analysis in this research.

\section{Discussion and Analysis}

There are various reasons as to why the Indian Ocean requires greater cooperation and sharing of resources. This section attempts to highlight a few significant reasons as to why cooperation via Maritime Domain Awareness is not only required, but almost overdue. In doing so, this section also attempts to provide answers to the three research questions, i.e. a) why is there inadequate cooperation within the Indian Ocean Region; b) how can the Indian Ocean littoral countries cooperate via Maritime Domain Awareness; c) how can users of the Indian Ocean cooperate via Maritime Domain Awareness in safeguarding the Indian Ocean. 


\section{a. Inadequate cooperation within the Indian Ocean}

Region. In ancient times, this ocean space has been an area of immense cooperation. Ships laden with raw material, commodities and products have traversed the Indian Ocean from east to west and vice versa. In fact, trade would have been the unifying factor which permitted friendly relations between the Indian Ocean littoral states and the extra-regional states. As such, concepts such as the 'Ancient Maritime Silk Road' are references to the Indian Ocean which was the "main trade route or ocean highway" 10 . Historical records indicate that the littoral states of the Indian Ocean have in fact cooperated with merchant ships from distant lands in exchanging spices, herbs and commodities for ceramics, silks and other important items of trade. Furthermore, the seaborne route was the preferred route in transporting large volumes of goods, thus, also encouraging a sense of kinship in protecting this precious area.

However, over the centuries, this kinship in protecting the Indian Ocean faded away into competition, with certain littoral states wanting to retain this area for themselves or regarding it as their own, and various extra-regional states wanting to dominate it and retain it as an 'enclosed area'11. This competition was further intensified by the numerous extra-regional powers such as the Portuguese, the Dutch and the British, that dominated the Indian Ocean and colonised its littoral states. Due to the power struggle among these states prior to the $20^{\text {th }}$ Century, the Indian Ocean became an area for conflict, rather than cooperation. However, the two World Wars and the Cold War thereafter, put a spotlight on the Indian Ocean for various reasons such as its locational significance, geographical features and resources. This

${ }^{10}$ Bandaranayake, S. "Introductory Note: Sri Lanka and the 'Silk Road' of the Sea," In Sri Lanka and the 'Silk Road'of the Sea, Eds., S. Bandaranayake, L. Dewaraja, R. Silva and K.D.G. Wimalaratne, (Colombo, Sri Lanka: Central Cultural Fund, 2007), 9-10.

${ }^{11}$ David Brewster, "Silk Roads and Strings of Pearls: The Strategic Geography of China's New Pathways in the Indian Ocean," Geopolitics, (2016), DOI: 10.1080/ 14650045.2016.1223631 
power struggle, thus witnessed more extra-regional powers such as the United States of America, the Soviet Union and France, to name a few, enter into the discourse pertaining to the Indian Ocean. Due to these power dynamics, Sri Lanka proposed the Indian Ocean Zone of Peace (IOZOP), a concept which was to assist in limiting the power play in the region and neutralising the effect of weapons of mass destruction (WMD) being utilised and transported.

Retrospectively, in the $20^{\text {th }}$ century too, the dynamics in the Indian Ocean proved to be intense and challenging. However, even though the epicentres for global events changed over the decades, scholars and professionals have once again regarded the Indian Ocean as the "heart of the world" in the $21^{\text {st }}$ Century, with many powers, both littoral and extra-regional, vying to have a large stake in this power play ${ }^{12}$.

Furthermore, insecurities and rivalries among powers such as China, India and the United States of America have heightened the need for maritime cooperation in this ocean space. These insecurities, competition and distrust are as a result of the increasing naval activity in the IOR as well as the competition for resources. Following a component of the national interest of their countries such as trade, the Indian Ocean is once again witnessing an increase in the world's navies. This is because state navies are seen following their commercial vessels, i.e. 'flags following ships', to ensure their commodities are secure. In addition to the increase in the naval presence in the Indian Ocean, the world is also witnessing an upsurge in the competition for resources.

At the 2018 Indian Ocean Conference held in Vietnam, Sri Lanka's Prime Minister Ranil Wickremasinghe pointed out that there appears to be a weakening of multilateral systems ${ }^{13}$. This is especially true when considering the Indian Ocean Region where there is a lack of cooperation and consensus among littoral states

12 Robert D. Kalpan., Monsoon: The Indian Ocean and the Future of American Power. (New York, USA:Random House, 2011)

13 "PM floats new platform by SL for Indian Ocean maritime cooperation," Daily FT, August 29, 2018, http://www.ft.lk/front-page/PM-floats-new-platform-bySL-for-Indian-Ocean-maritime-cooperation/44-661794 
on what needs to be done in the region, which is further heightened by the involvement of the region's users. The region is also confounded with the problem of not having one single organisation with members from all the Indian Ocean littoral states. This region currently boasts of various regional fora on maritime security such as the Indian Ocean Regional Organisation (IORA), the Indian Ocean Naval Symposium (IONS), the Indian Ocean Tuna Commission (IOTC), the Indian Ocean MOU (IOMOU) on Port State Control, the UNESCO Intergovernmental Oceanographic Commission (IOC), and the UNESCO IOC Intergovernmental Coordination Group for the Indian Ocean Tsunami Warning and Mitigation System (ICG/IOTWS) ${ }^{14}$. All these regional groupings have their own agendas. IORA, for example, which was formed in 1997 is an intergovernmental organisation that annually hosts a Foreign Ministers' meeting (Indian Ocean Rim Association ${ }^{15}$. It is also the only regional organisation that links most of the Indian Ocean states. Whilst the organisation was originally established to promote economic cooperation, it has since widened its agenda to eight priority areas, amongst which are maritime safety \& security, disaster risk management, academic, science \& technology. However, the undesirable factor of this organisation is that it is not inclusive, as littoral states such as Pakistan are not giving membership. IONS, for instance, convenes the Naval Chiefs of the Indian Ocean littoral states and its users ${ }^{16}$. It has three working groups on humanitarian assistance \& disaster relief (HADR), maritime security and information sharing \& interoperability (Indian Ocean Naval Symposium ${ }^{17}$. This forum provides a much required opportunity for the navies of this region to interact and deliberate

14 "Department of Foreign Affairs and Trade, Australia," Indian Ocean regional forums.( n.d. ), https://dfat.gov.au/international-relations/ regionalarchitecture/indian-ocean/Pages/indian-ocean-regional-forums.aspx

15 "About IORA", Indian Ocean Rim Association, 2017, https://www.iora.int/en

16 Joint Chiefs of Staff, Department of Defense Dictionary of Military and Associated Terms, (2016).

17 "IONS Working Group" Indian Ocean Naval Symposium, (2018), http://www.ions.global/ 
on issues that are of importance. This differs from the norm where only the bureaucrats meet and discuss on mutual matters. Even though the IOR enjoys these organisations and fora, they do not provide membership to all of the Indian Ocean's littor al states or its users. Incidents such as this, increases or sharpens the distrust harboured among states, thereby leading to insecurities in the maritime domain.

In addition to the above, the Indian Ocean is ripe with distrust. Both the littoral states and the extra-regional states do not place absolute trust in one another to cooperate, to find solutions to the problems the region faces or to safeguard the region. Thus, even though the region has received adequate attention, there is still inadequate cooperation within the IOR to solve the region's challenges in the maritime sphere.

b. Cooperation between Indian Ocean littoral states to ensure maritime security. As present challenges are diverse and multifaceted, countries are singularly unable to ensure their maritime borders are safe unless they have shared intelligence and information from a variety of sources. In roughly a decade between 1992 and 2002, shipping traffic in the Indian Ocean has increased by approximately 300 per cent ${ }^{18}$. The reaction by extraregional powers to the energy flows in the Indian Ocean region largely determines how the region's trade occurs ${ }^{19}$. Further, the "stability and security" of the region determines how energy shipments traverse externally. The increase and the diversity of trade and commerce too have made it crucial for MDA to occur. In this context, Maritime Domain Awareness has a large part to play in intelligence sharing, as well as in shared capabilities and resources.

${ }_{18}$ Panditaratne, D. "The Role of Sri Lanka in South Asia and Beyond: Emerging New Contours," Research and Information System for Developing Countries, 19 January, (2018),

https://www.lki.lk/wp-content/ uploads/ 2018/02/LKI\%E2\%80\%99s-DinushaPanditaratne-on-the-Role-of-Sri-Lanka-in-South-Asia-and-Beyond-at-RIS-inIndia.pdf

19 Cordesman, Burke, Berntsen, Dewit, Toukan, "The Indian Ocean Region: A Strategic Net Assessment", Centre for strategic and international studies, (2014): 55 . 
This is important as the oceans are too vast a frontier for any one country to be able to monitor alone.

Non-Traditional Security Threats are diverse and difficult for a single country to counter. It needs the collective involvement of stakeholders to ensure there is cooperation in ensuring state actors have information about the perpetrators, the material that is being illegally smuggled - be it humans, drugs, gold, arms and ammunition etcetera. Towards this end, Maritime Domain Awareness is useful as the Indian Ocean littoral states can share intelligence on vessels carrying illegal products or are engaging in illegal activities, thereby creating avenues to intercept such activities. Regional cooperation by way of shared intelligence would pave the way for littoral states to work together as a team, as oppose to working in silos or individually. Accordingly, demonstrating good neighbourly relations in the IOR, India has assisted island-states such as Seychelles, Maldives and Mauritius improve their maritime domain awareness by installing coastal radars and conducting surveillance in their Exclusive Economic Zone (EEZ). India has also assisted Maldives and Sri Lanka by sharing information through its maritime security trilateral ${ }^{20}$. Success stories such as the above are important in improving and encouraging cooperation and interaction between the littoral states of the Indian Ocean.

An increase in maritime security cooperation would also permit states to be more networked, similar to these transnational organised crime (TOC) groups, thereby having an advantage in dismantling such illegal networks. Therefore, Maritime Domain Awareness would pave the way for the Indian Ocean littoral states to cooperate with one another. Australia-Sri Lanka can be cited as a useful example towards the successful bilateral information and intelligence sharing between two states. Sharing of vital intelligence between the navies and border security agencies of the two states enabled them to thwart many illegal networks, that were smuggling ship loads of people from post-conflict Sri Lanka to

20 Nilanthi Samaranayake, "Views from India's Smaller Maritime Neighbors", Asia Maritime Transparency Initiative, June 18, (2015), https://amti.csis.org/views-from-indias-smaller-maritime-neighbors/ 
Australia. The cooperation between the navies of the two countries, the information they also received from third countries such as Malaysia and Indonesia, were also imperative in eliminating these TOC networks. Furthermore, the public awareness campaigns carried out by Australia in Sri Lanka were also extremely important. Accordingly, these showcases the success states can derive from maritime domain awareness towards enabling maritime security in the Indian Ocean region by building trust.

Another area, in which there can be greater cooperation in the Indian Ocean, is in tackling oceanic pollution. Currently there are five offshore plastic accumulation zones in the world with the second largest being in the Indian Ocean. The Indian Ocean garbage patch which was discovered in 2010 constitutes a wide area of at least five million square kilometres and has no specific or clearly recognisable boundaries ${ }^{21}$. Therefore, conducting surveys on the second largest oceanic plastic accumulation and understanding the damage it is doing to the marine environment is crucial in ensuring the Indian Ocean region is an environmentally clean space. Curtailing oceanic pollution is an area where the IOR countries can partake in to implement measures that need to be taken to instil practices of sustainable consumption within the citizens of the littoral states, especially the youth population.

A further avenue for cooperation between the Indian Ocean littoral states is to share information on the Automatic Identification System (AIS) of vessels. An AIS is "an automated, autonomous tracking system which is extensively used in the maritime world for the exchange of navigational information between AIS-equipped terminals" 22

${ }^{21}$ Laura Parker, "Plane Search Shows World's Oceans Are Full of Trash", National Geographic, (April 4, 2014), https://news.Nationalgeogra phic.com/news/2014/04/140404-garbage-patch-indian-ocean-debris-malaysianplane/

22 Maritime Traffic (n.d.). What is the Automatic Identification System (AIS)? , https://help.marinetraffic.com/hc/en-us/articles/204581828-What-is-the-

Automatic-Identification-System-AIS- 


\section{c. Collaboration between users of the Indian Ocean Region to ensure maritime security.}

MDA is important in this instance as it can generate actionable intelligence ${ }^{23}$. Cooperation between the Indian Ocean countries can include the interception of vessels carrying illegal goods as well as flora and fauna, before they cross the Indian Ocean either to transit or to reach their final destination. As much as the littoral states' maritime intelligence is superior along its immediate periphery, it requires additional support from the likes of the Unites States and China, in curtailing various non-traditional security threats in the greater Indian Ocean region. Collective efforts by both the Indian Ocean states and its users would be an added advantage to ensure there is global cooperation in safeguarding this ocean space. Therefore, sharing of information and intelligence can be useful in formulating a Common Operating Picture (COP), which will also benefit the users of the ocean to be safeguarded against illegal activities. In this instance, satellite imagery can be obtained for deep sea surveillance, navigation and to gather information about the greater Indian Ocean Region to help monitor the area. In addition, utilising the submarine capability which is possessed by countries such as Australia, India and Pakistan as well as extra-regional states such as China, United States, Russia would be useful in sharing any vital information its vessels intercept of subsurface illegal activities such as pollution, harming coral reefs, that are detrimental to the oceanic environment ${ }^{24}$.

${ }_{23}$ Marine Insight, (2016, July 21). A General Overview of Maritime Domain Awareness (MDA). ( July 21, 2016), https://www.marineinsight.com/maritimelaw/a-general-overview-of-maritime-domain-awareness-mda/

${ }^{24}$ Grooten M. and Almond, Living Planet Report - 2018: Aiming Higher, WWF, (Gland, Switzerland, 2018). 
A further area wherein the Indian Ocean littoral states and its users can cooperate is in tracking oil spills in this ocean space. At present, is it difficult for a single country or for countries to monitor such oil spills without proper satellite imagery. For example, Sri Lanka, which is centrally located in the Indian Ocean Region, does not have adequate technology to monitor such situations. Even though Sri Lanka Coast Guard (SLCG) is trained and equipped to contain any oil spill that could occur, the lack of adequate technological infrastructure and support hamper its ability to be a useful institution to the region. In such an instance sharing of technology, skills and information by countries that possess such capabilities such as India, China and the United States would be helpful to a littoral state such as Sri Lanka, which has a large ocean space to monitor and secure. Although there is no immediate threat, a threat of this nature could be a possibility in the future. Being situated astride the busiest shipping lane in the Indian Ocean, it is important for Sri Lanka to have the necessary mechanisms to monitor oil spills. In addition, sharing of information and capabilities also enables these countries to ensure there is maritime security in the Indian Ocean region and al so to reduce their trust deficit. Thus, this is another mechanism for the littoral states and the users of the Indian Ocean to implement in building their confidence and trust in one another to make the ocean space more safe and secure.

Alongside the increase in trade and commerce, communication and technology too has enabled the spiralling of challenges and threats to security. This has led to an increasing number of diverse and fluid networks, cutting across society whilst remaining untraceable. These networks and tools have also led to the permeation of non-traditional security threats and a greater difficulty in them being traced due to their clandestine nature. Improved communication technology and access to social media has also proliferated the number of non-state actors who are involved in illegal activities and also how they engage in them. Therefore, sharing intelligence of these clandestine groups and their activities would enable the states authorities to curtail their physical and virtual activities. Sharing intelligence of this nature and ensuring countries utilise the intelligence shared for ge nuine and legal purposes will also guarantee an increase in trust in the Indian Ocean region. 
An additional area wherein Sri Lanka requires assistance is in tracking oil spills in the Indian Ocean. At present, Sri Lanka does not have adequate technology to monitor such situations, even though Sri Lanka Coast Guard is trained and equipped to contain any oil spill that could occur. Although there is no immediate threat, this could be a possibility at any given moment or in the future. Being situated astride the busiest shipping lane in the Indian Ocean, it is important for Sri Lanka to have the necessary mechanisms to monitor oil spills. On similar lines, Sri Lanka does not have a system to monitor whether ships are by chance releasing burnt fuel into the Indian Ocean. Regardless of their being international laws prohibiting such activity, it is still very important to be able to monitor the activities of the ships sailing past the country. This can be two-fold in terms of monitoring the release of burnt fuel as well as in being aware of the kind of ships sailing by. It can be a further advantage as it will enable navies to also know the kind of cargo that is on-board the vessel. Additionally, it would be useful for countries such as Sri Lanka to obtain infor mation on ships that do not switch on their Automatic Identification System (AIS) when sailing past Sri Lanka. Currently, Sri Lanka has no way to track ships that disable their AIS and know what kind of activities these vessels are involved in, in Sri Lanka's periphery. Towards this end, actionable intelligence from littoral states such as Australia, India and Pakistan as well as extra-regional states such as China and the United States would be vastly advantageous to Sri Lanka. However, it would be ideal for Sri Lanka to possess drones and surveillance syste ms to monitor vessels traversing the Southern coast of the island. Therefore, establishing a hub in Sri Lanka to coordinate maritime security requirements in the Indian Ocean region would be a subsequent measure the Indian Ocean countries could strive to establish to ensure there is an increase in trust.

As mentioned earlier on in sub-section one of this paper, the Indian Ocean has several multilateral institutions to safeguard its waters. However, these fora and organisations do not provide membership to all the littoral states of the Indian Ocean as well as its users. Therefore, these organisations' usefulness and 
operational capabilities can be contested as they do not create a common platform for consensus among these powers. In this backdrop, Sri Lanka called for a multi-layered system, at the 2018 Indian Ocean Conference held in Vietnam, which does not take countries' geographical constraints into consideration and is inclusive $^{25}$. As important as it is for countries to individually support and initiate programmes to improve maritime security in the Indian Ocean, it is equally important for countries to work together under a common understanding and on a common platform. Hence, it is important to have multinational organisations that are inclusive in nature. Therefore, it would be appropriate to incorporate the functions of all the aforementioned fora and organisations and create one common entity that will provide membership status to all the littoral states and the users of the Indian Ocean. Whilst being inclusive in nature, a common platform to coordinate activities in the IOR would also be useful in carrying out relief measures during natural disasters. For that reason, it would be practical to have the foreign ministers and the naval chiefs of countries working together within a single organisation to enable prompt action. Thus, it can be considered that a common, inclusive multinational organisation for the Indian Ocean Region is important to dispel mistrust and to attract countries to one another.

\section{Conclusion}

There are many avenues for Indian Ocean littoral countries to cooperate on, especially in ensuring there is maritime security in their common neighbour, i.e. the Indian Ocean. Ensuring there is cooperation for the ocean's well-being assures that it is held in trusteeship for the future generations to also consume. As the Indian Ocean is a public good, it needs to be taken care of by all its inhabitants as well as its users. The third-largest ocean body can only be protected for future generations, if there is a high degree of collaboration between states. Therefore, MDA, where there is sharing of information and intelligence would be in the best interest bilaterally between specific states, as well as

25 "PM floats new platform by SL for Indian Ocean maritime cooperation", Daily FT, August 29, (2018), http://www.ft.lk/front-page/PM-floats-new-platform-bySL-for-Indian-Ocean-maritime-cooperation/44-661794 
multilaterally, for the betterment of the entire world. Accordingly, a multilateral involvement or the need to have an inclusive multilateral engagement in the Indian Ocean region needs to be emphasised. This is because only a multilateral engagement everyone believes in would be able to ensure there is a shift in perspective from mistrust to trust and countries would be confident in cooperating with one another in the maritime domain. Therefore, a multinational organisation which provides membership to all the littoral states of the Indian Ocean and its users as well as function as an umbrella organisation would be the call of the day in improving maritime cooperation.

Even though there is an inherent distrust between the littoral states in sharing vital intelligence, it needs to be noted that cooperation by way of sharing resources, intelligence, skills and manpower amongst each other would also benefit the littoral states overcome this mistrust. Thereby, enhancing cooperation between the states.

Therefore, if cooperation between the littoral states and the users of the Indian Ocean could focus on immediate areas such as non-traditional security threats, environmental degradation, pollution, monitoring of vessels and oil spills, insecurities in the region could be curtailed to a larger extent. There are many avenues for Indian Ocean littoral countries to cooperate on, for instance by way of sharing information and intelligence between countries such as China, India, Pakistan, Sri Lanka and the United States, especially in ensuring there is greater co operation in maritime security and the Indian Ocean is safeguarded for the future generations. 